\title{
A Quantitative Dot-Blot Immunoassay for Integral Membrane Proteins: Preparation of Pancreatic Plasma Membranes Containing Apical and Basolateral Domains
}

\author{
Robert C. De Lisle ${ }^{1}$ \\ Department of Physiology, University of Michigan, Ann Arbor, Michigan 48109
}

Received May 9, 1990

Modifications of standard dot-blot immunoassay techniques have been made for the quantitation of integral membrane protein antigens. The modification involves the signal development step, which is performed by using punched-out wells of the solid support (nitrocellulose) to yield a soluble colored reaction product. This approach avoids the inhomogeneity of an insoluble reaction product and the subsequent quantitation problems encountered when such product is scanned by densitometry. The method was validated by comparing the purification and overall recoveries of a known plasma membrane enzymatic marker with integral membrane antigens of defined localization during subcellular fractionation of mouse pancreas. The final plasma membrane fraction contained both basolateral ( $\sim 20$-fold enriched) and apical membrane ( $\sim$-fold enriched) domains. (c) 1991 Academic Press, Inc.

A large number of immunoassays exist that are based on a variety of methodologies [for review see (1-4)]. Many assays have been developed for quantitation of specific soluble molecules of interest, but only a few assays have been designed to provide systems useful for quantitation of membrane antigens $(5,6)$. These assays have not been sufficiently characterized for reliable quantitation of membrane antigens in different subcellular fractions. The objective of the work reported here was to develop an immunoassay for quantitation of integral membrane antigens in complex mixtures during subcellular fractionation. The assay is currently being used to develop methods to subfractionate pancreatic acinar cell plasma membranes into apical and basolat-

\footnotetext{
${ }^{1}$ Present address and address for reprint requests: Dept. Anatomy and Cell Biology, University of Kansas Medical Center, Kansas City, KS 66103.
}

eral fractions. A variation of the assay is also being used to screen for hybridomas producing monoclonal antibodies to membrane antigens.

\section{MATERIALS AND METHODS}

Reagents. Sheep anti-rat Ig- $\beta$-galactosidase was obtained from Amersham (Naperville, IL). Nitrocellulose paper $(0.45-\mu \mathrm{m}$ pore size) was obtained from Bio-Rad (Richmond, CA). All other chemicals were obtained from Sigma Chemical (St. Louis, MO).

Subcellular fractionation of mouse pancreas. Plasma membranes were prepared from mouse pancreas using an adaptation of an established technique $(7,8)$. All steps were performed at $4{ }^{\circ} \mathrm{C}$. Mouse pancreatic tissue was minced with scissors and suspended in $1 \mathrm{mM}$ $\mathrm{NaHCO}_{3}, \mathrm{pH} 7.4,0.5 \mathrm{mM} \mathrm{MgCl}_{2}, 0.1 \mathrm{mM}$ phenylmethylsulfonyl fluoride, and $1 \mathrm{mM}$ benzamidine at $1 \mathrm{~g}$ tissue $/ 5$ $\mathrm{ml}$ buffer. The suspension was homogenized for $30 \mathrm{~s}$ at setting 5 with a Brinkman homogenizer (Brinkman Instruments, Westbury, NY), followed by three strokes with a glass-Teflon homogenizer at $1300 \mathrm{rpm}$. The homogenate was centrifuged to pellet unbroken cells by accelerating the centrifuge to $1300 \mathrm{~g}$ and then stopping immediately. The pellet was rehomogenized and pelleted as above and the two supernatants were combined. The combined supernatants were considered as the homogenate which was then diluted 20-fold in the same buffer without $\mathrm{MgCl}_{2}$ and plus $0.7 \mathrm{mM}$ EDTA, and incubated on ice for $10 \mathrm{~min}$. The homogenate was filtered through four layers of gauze and was centrifuged at $1300 \mathrm{~g}$ for $15 \mathrm{~min}$ to pellet large membrane sheets. The upper surface of this pellet (the "fluffy" layer) was rinsed off with homogenization buffer and the remaining pellet was considered as the crude plasma membrane fraction. The crude plasma membranes were resuspended in $46 \%$ sucrose $(w / v)$ in a Dounce homogenizer with a tight pestle (pestle A), placed into 
SW 41 centrifuge tubes, overlaid with $10 \%$ sucrose, and centrifuged for $2 \mathrm{~h}$ at $38,000 \mathrm{rpm}$. The purified plasma membranes were removed from the interface, washed in phosphate-buffered saline (PBS; ${ }^{2} 20 \mathrm{mM} \mathrm{PO}_{4}, 150 \mathrm{mM}$ $\mathrm{NaCl}, \mathrm{pH} 7.4$ ) by ultracentrifugation, resuspended in PBS at $\sim 1 \mathrm{mg}$ protein per $\mathrm{ml}$, and stored at $-70^{\circ} \mathrm{C}$.

Monoclonal antibodies. The monoclonal antibodies used were produced by fusion of the mouse myeloma SP2/0-Ag14 with rat spleen cells by conventional methods (9). Acinar-1, one of the monoclonal antibodies $(\mathrm{mAb})$ used in this study, has been described previously (8) and was raised against a primary monolayer culture of mouse acinar cells. The other mAb used in the current study, 4.1B12, was obtained by immunizing rats with $1 \%$ Triton $\mathrm{X}-100$ solubilized plasma membranes prepared as above. The characteristics of the mAbs are described under Results.

Standard dot-blot immunoassay protocol. Samples for assay were suspended at $4^{\circ} \mathrm{C}$ in Tris-buffered saline (TBS; $10 \mathrm{mM}$ Tris, $\mathrm{pH} 7.0,150 \mathrm{mM} \mathrm{NaCl}$ ) at protein concentrations of $0.1 \mathrm{mg} / \mathrm{ml}$ and disrupted by sonication on ice with a probe-type sonicator (Branson Ultrasonics Corp., Danbury, CT) for $5 \mathrm{~s}$ at a $60-\mathrm{W}$ output. Serial twofold dilutions were made in TBS and applied to $0.45-\mu \mathrm{m}$ pore size nitrocellulose in a commercial dotblot apparatus (Bio-Rad). The apparatus was then disassembled and the nitrocellulose was placed in $10 \mathrm{ml}$ of blocking solution (3\% bovine serum albumin, $0.05 \%$ Tween-20, in PBS) and incubated with gentle agitation for $2 \mathrm{~h}$ at room temperature. After blocking, $10 \mathrm{ml}$ of mAb-containing spent hybridoma culture supernatant (10\% fetal bovine serum in RPMI-1640 medium) was added to the blocking solution and incubated overnight at $4^{\circ} \mathrm{C}$ with gentle agitation. The nitrocellulose was then washed $4 \times 10$ min with $25 \mathrm{ml}$ of $0.05 \%$ Tween-20 in PBS. Next, the nitrocellulose was incubated with 10 $\mathrm{ml}$ of sheep anti-rat $\beta$-galactosidase-coupled second antibody diluted 1:1250 in blocking solution for $2 \mathrm{~h}$ at room temperature with agitation and then washed again as above. For the enzymatic readout, the individual samples were punched out from the nitrocellulose with an eight-channel punch of $6 \mathrm{~mm}$ diameter (designed and built in the Physiology Department Machine Shop) and transferred to wells of a 96-well plate. Sample blanks were obtained by punching out areas of the nitrocellulose between the wells used for samples. A 100- $\mu$ l sample of substrate solution ( $3 \mathrm{mM} o$-nitrophenyl galactopyranoside (oNPG), $10 \mathrm{~mm} 2$-mercaptoethanol, $10 \mathrm{~mm}$ $\mathrm{MgSO}_{4}$, in PBS) was added, and the samples were incubated until sufficient color developed, usually $0.5-2 \mathrm{~h}$ at room temperature. The reaction was stopped with $50 \mu \mathrm{l}$

\footnotetext{
${ }^{2}$ Abbreviations used: PBS, phosphate-buffered saline; TBS, Trisbuffered saline; oNPG, o-nitrophenyl galactopyranoside; SDS, sodium dodecyl sulfate; $p$ NPPase, $p$-nitrophenyl phosphatase.
}

of $1 \mathrm{M} \mathrm{Na}_{2} \mathrm{CO}_{3}$, and the reaction product was transferred to a clean 96-well plate. The $O D_{405} \mathrm{~nm}$ was read using a multiwell plate reader (Flow Labs, McLean, VA), which was zeroed using the reaction product from sample blanks prepared as described above.

Variation of the assay to screen for hybridomas producing $m A b$ against membrane proteins. A variation of the assay was made which allows testing of large numbers of hybridoma culture supernatants as a screening procedure for $\mathrm{mAb}$ against membrane fractions. The same amount of membrane protein was applied to each well in the dot-blot apparatus and the samples were punched-out and placed in 96 well plates. All the incubations were then carried out in the 96-well plates, allowing different primary mAbs to be used for each sample. With this method, it was possible to screen $\sim 2000$ wells for membrane antigen-specific $\mathrm{mAb}$ production in a single run covering 2 days time.

Data analysis. The immunoassay was designed to be a pseudo-first-order reaction (see Results) such that the signal would be linearly related to the amount of antigen in the sample. The data were analyzed by linear regression of the $O D_{405 \mathrm{~nm}}$ vs micrograms of sample and the slopes of these lines were taken as the specific activities of the antigen in the samples. Regression coefficients usually exceeded 0.9 .

Immunoblots of Western-transferred protein. Plasma membranes were run on a $7.5 \%$ polyacrylamide-SDS gel with 2-mercaptoethanol followed by Western transfer to nitrocellulose (10). Immunoblots of Western transferred plasma membranes were performed as previously described (8) to determine antigen molecular masses.

Electron microscopic immunoperoxidase labeling. A preembedding immunoperoxidase technique was used for mAb-binding localization as previously described $(8,11)$.

$K^{+}$-stimulated pNPPase assay and protein determination. $\mathrm{Na}^{+} / \mathrm{K}^{+}-\mathrm{ATPase}$ activity was measured as potassium-stimulated $p$-nitrophenyl phosphatase ( $p$ NPPase) activity as previously described (8) on fresh samples. Protein was measured on samples solubilized by boiling in $0.1 \mathrm{~N} \mathrm{NaOH}$ using the Bradford method (12) with a commercial reagent (Bio-Rad).

\section{RESULTS AND DISCUSSION}

Characterization of the monoclonal antibodies. Two mAbs were used for these studies. Acinar- 1 has been described previously (8) and is a rat $\operatorname{IgG}_{2 a}$ that recognizes a $94-\mathrm{kDa}$ protein localized by indirect immunofluorescence and electron microscopic immunoperoxidase labeling to the apical plasma membrane domain of a number of murine exocrine cell types, including the pancreatic acinar cell. The other mAb, currently designated 


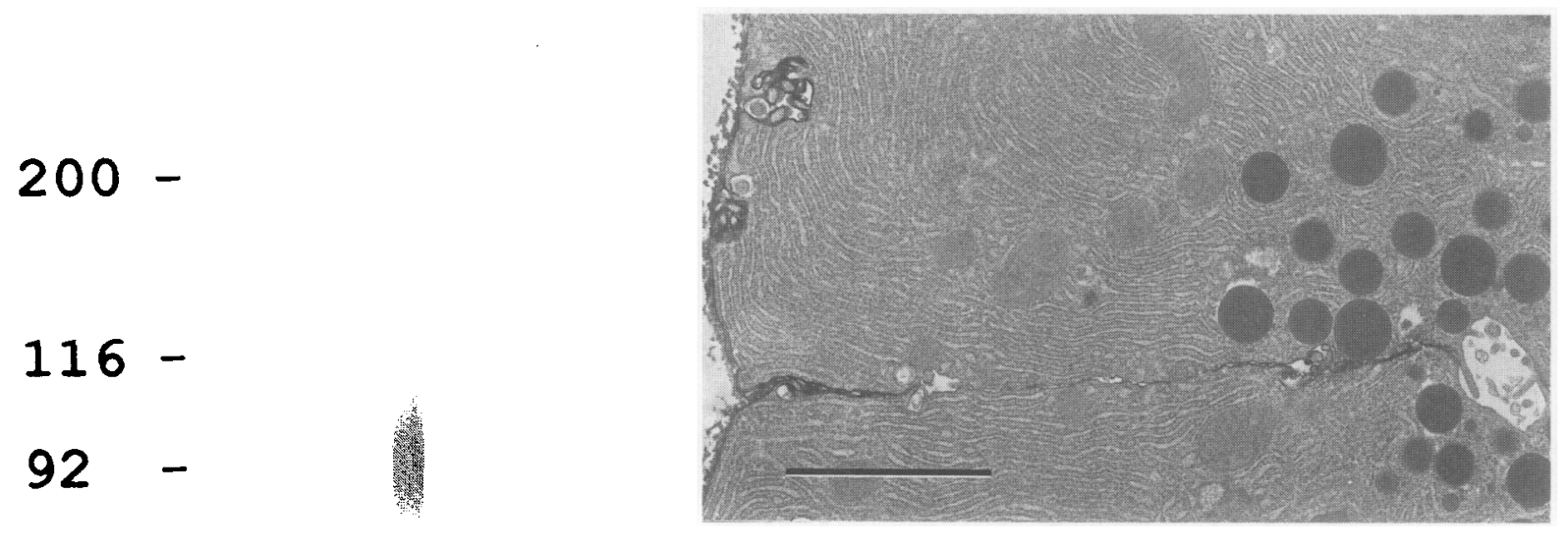

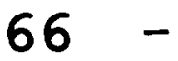

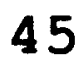

\section{kDa}

FIG. 1. Immunoblat of Western-transferred plasma membrane protein. The nitrocellulose was immunoblotted with mAb 4.1B12 (left lane) and mAb Acinar-1 (right lane). The molecular weight standards are as indicated in the figure.

4.1B12, is also a rat $\operatorname{IgC}_{2 \mathrm{a}}$ which recognizes a $32-\mathrm{kDa}$ protein of mouse pancreatic acinar cells. A Western blot shown in Fig. 1 demonstrates the molecular weight determination for these antigens using isolated pancreatic plasma membranes. By indirect immunofluorescence (not shown) and electron microscopic immunoperoxidase labeling (Fig. 2), 4.1B12 labels the basal and lateral membrane domains of acinar cells with no detectable labeling of the apical membrane domain. The membrane proteins studied in this work were integral membrane proteins, as determined by the inability of $0.1 \mathrm{M}$ $\mathrm{Na}_{2} \mathrm{CO}_{3}$ to solubilize them (not shown).

Design of the immunoassay. Initial attempts were made to use a solid-phase enzymatic immunoassay whose end product was an insoluble deposit on nitrocellulose paper $(13,14)$. This approach did not work well to quantitate antigens in various membrane fractions. The major problem was uneven development of reaction product on the nitrocellulose which made quantitation
FIG. 2. Electron microscopic immunoperoxidase labeling of mouse pancreatic tissue with $\mathrm{mAb}$ 4.1B12. Note that the label is restricted to the basal and lateral plasma membrane domains and that the apical plasma membrane is not labeled. Scale bar, $2.5 \mu \mathrm{m}$.

by reflectance densitometry unreliable. This may have been due to the particulate nature of the samples (membrane sheets and vesicles) and uneven deposition on the nitrocellulose. Therefore, the assay was adapted to produce a soluble end product which could be reliably quantitated by absorption spectrophotometry. The assay was designed to obtain a pseudo-first-order relationship between the amount of antigen applied and the signal observed. To achieve this, the amount of antigen was limiting and all other reagents were applied at saturating levels. Therefore, the form of the data assumes a linear relationship between antigen and signal and is easily analyzed by linear regression to obtain a slope, which gives a specific activity value for the antigen content of the sample.

Color development. Details of the assay are given under Materials and Methods. Up until the final step, color development, the nitrocellulose remained as a sin-

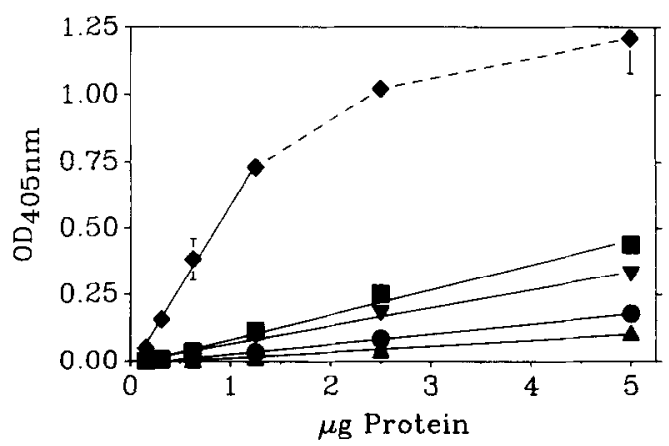

FIG. 3. Immunoassay with mAb $4.1 \mathrm{~B} 12$ of different subcellular fractions obtained during plasma membrane preparation. The samples were: homogenate (circles); supernatant (triangles); fluffy layer (squares); crude plasma membranes (inverted triangles); and final plasma membranes (diamonds). Data are means \pm SD from triplicate determinations from a representative experiment. 
TABLE 1

Balance Sheet for Immunoreactivities and pNPPase Activity in Subcellular Fractions of Mouse Pancreas during Plasma Membrane Preparation

\begin{tabular}{|c|c|c|c|c|c|c|}
\hline \multirow[b]{2}{*}{ Sample } & \multicolumn{2}{|c|}{$\begin{array}{l}\text { mAb 4.1B12 } \\
\text { (basolateral) }\end{array}$} & \multicolumn{2}{|c|}{$\begin{array}{c}p_{\text {NPPase }}^{a} \\
\text { (basolateral) }^{\text {Natel }}\end{array}$} & \multicolumn{2}{|c|}{$\begin{array}{c}\text { mAb Acinar-1 } \\
\text { (apical) }\end{array}$} \\
\hline & Enrichment $^{b}$ & $\%$ of total ${ }^{e}$ & Enrichment & $\%$ of total & Enrichment & $\%$ of total \\
\hline Supernatant & $0.60 \pm 0.04$ & $44 \pm 5.2$ & $0.47 \pm 0.12$ & $34 \pm 6.2$ & $1.0 \pm 0.14$ & $75 \pm 5.7$ \\
\hline Fluffy layer & $2.9 \pm 0.68$ & $46 \pm 11$ & $2.7 \pm 0.00$ & $44 \pm 0.58$ & $1.7 \pm 0.21$ & $27 \pm 3.0$ \\
\hline Crude $\mathrm{PM}^{d}$ & $1.9 \pm 0.69$ & $8.5 \pm 2.2$ & $1.8 \pm 0.21$ & $8.3 \pm 2.3$ & $1.2 \pm 0.25$ & $5.6 \pm 0.68$ \\
\hline Final PM & $21 \pm 4.5$ & $4.4 \pm 0.95$ & $22 \pm 2.8$ & $4.8 \pm 1.9$ & $4.4 \pm 0.23$ & $0.94 \pm 0.25$ \\
\hline Recovery $^{e}$ & & $99 \pm 15$ & & $86 \pm 5.6$ & & $108 \pm 6.1$ \\
\hline
\end{tabular}

${ }^{a} \mathrm{Na}^{+} / \mathrm{K}^{+}-\mathrm{ATPase}$ activity measured as $\mathrm{K}^{+}$-stimulated pNPPase activity.

${ }^{b}$ Values are relative to the homogenate specific activity, which was defined as unity.

c Values are relative to the total activity of the homogenate, which was defined as $100 \%$.

The abbreviation PM stands for plasma membrane.

e Recoveries were calculated from the sum of activities in the supernatant plus fluffy layer plus crude PM fractions as percent of tatal activity in the homogenate. All values are the means \pm SD from three independent preparations.

gle piece which made all the necessary handling in the preceding steps easy and rapid. Now, the individual spots containing the samples were punched out so that they could be separately incubated with the chromogenic substrate, $o \mathrm{NPG}$, in 96 -well plates.

Linearity of the reaction. A typical assay result is shown in Fig. 3 using the basolateral mAb 4.1B12 and the different fractions obtained during membrane preparation. The signal was linearly related to the amount of sample up to the point where the amount of antigen is no longer the limiting factor. The capacity of the nitrocellulose for protein binding is estimated to be $80 \mu \mathrm{g} /$ $\mathrm{cm}^{2}$ (15), which corresponds to $25 \mu \mathrm{g} / 0.32 \mathrm{~cm}^{2}$ sample well, so samples of low antigen content relative to total protein can be assayed. The linear correlation coefficients for the data in Fig. 3 were 0.999 for the homogenate, 0.984 for the supernatant, 0.995 for the fluffy layer, 0.996 for the crude plasma membrane fraction, and 0.998 for the final plasma membrane fraction. The enrichments, compared to the homogenate, of $4.1 \mathrm{~B} 12$ immunoreactivity (basolateral marker), $\mathrm{K}^{+}$-stimulated pNPPase activity (basolateral marker, [16]), and acinar-1 immunoreactivity (apical marker) are shown in Table 1. Note that the enrichments of 4.1B12 immunoreactivity and $\mathrm{K}^{+}$-stimulated $p N P P a s e$ activity parallel each other, as is expected since both are localized to the basolateral plasma membrane. The final plasma membrane fraction was enriched $\sim 20$-fold for both basolateral markers. In addition, the final plasma membrane fraction was enriched about 4-fold in the apical marker, Acinar-1 immunoreactivity, compared to the homogenate. Thus, plasma membranes prepared as described contain both basolateral and apical membrane domains.

Quantitative recovery of immunoreactivities. Other assays for quantitating membrane antigens have been described $(5,6)$. In determining whether those assays were quantitative, the authors demonstrated that the signal obtained was proportional to the amount antigen in a given sample, as was carried out for the current assay as described above. A more rigorous test of the quantitative nature of an assay and its general applicability is whether overall recoveries of activities in different subcellular fractions are obtained. If this criterion is met, then the assay is of general usefulness to measure antigen content in various samples of complex composition. An overall balance sheet using the different fractions obtained in preparing plasma membranes is shown in Table 1 . The recoveries of immunoreactivities were near $100 \%$ for both $\mathrm{mAbs}$, and a little less for the enzyme, which may be somewhat labile. Thus, the assay is quantitative using different subcellular fractions as well as serial dilutions of a single sample.

Conclusions. The enzymatic dot-blot assay described here is a quantitative immunoassay for integral membrane proteins giving good overall recovery values for different subcellular fractions. This assay is similar to the enzyme-linked immunofiltration assay of IJsselmuiden et al. (17), except that here the color development step takes place in 96-well plates and does not tie up the filtration device. This allows a greater number of samples to be assayed at one time. The assay described here is also relatively rapid and has the capacity to handle a large number of samples. This assay does not require pure antigen as long as relative activities and enrichments are sufficient. A variation of the assay allows the screening of large numbers of hybridomas for membrane fraction specific mAbs.

\section{ACKNOWLEDGMENTS}

This work was supported by NIH Grant GM 41388 and pilot project funds from the Michigan Gastrointestinal Peptide Reseurch Center. I 
thank B. Göke for a critical reading of the manuscript, E. Roach for expert technical assistance, and $\mathrm{K}$. Barald for use of a microplate reader.

\section{REFERENCES}

1. Hubbuch, A., Debus, E., Linke, R., and Schrenk, W. J. (1986) Prog. Clin. Biochem. Med. 4, 109-143.

2. Stott, D. I. (1989) J. Immunol. Methods 1 19, 153-187.

3. Tijssen, P. (1985) Practice and Theory of Enzyme Immunoassays, Elsevier, New York.

4. Towbin, H., and Gordon, J. (1984) J. Immunol. Methods 72, 313340 .

5. Noteboom, W. D., Knurr, K. E., Kim, H. S., Richmond, W. G., Martin, A. P., and Vorbeck, M. L. (1984) J. Immunol. Methods 75, 141-148.

6. Doeberitz, M. V. K., Drzonek, H., Koch, S., and Becker, C.-M. (1989) J. Immunol. Methods 122, 259-264.

7. Arvan, P., and Castle, J. D. (1982) J. Cell Biol. 95, 8-19.
8. De Lisle, R. C., Logsdon, C. D., Hootman, S. R., and Williams, J. A. (1988) J. Histochem. Cytochem. 36, 1043-1051.

9. Campbell, A. M. (1984) Monoclonal Antibody Technology, Elsevier, New York.

10. Towbin, H., Staehelin, T., and Gordon, J. (1979) Proc. Natl. Acad. Sci. USA 76, 4350-4354.

11. Osamura, R. Y., and Wantanabe, K. (1985) J. Electron Microsc. Tech. 2, 569-576.

12. Bradford, M. M. (1976) Anal. Biochem. 72, 248-254.

13. Ogata, F. (1989) J. Immunol. Methods 116, 131-135.

14. Van Vooren, J. P., Turneer, M., Yernault, J. C., De Bruyn, J., Burton, E., Legros, F., and Farber, C. M. (1988) J. Immunol. Methods 113, 45-49.

15. Gershoni, J. M., and Palade, G. E. (1982) Anal. Biochem. 124, 396-405.

16. Hootman, S. R. (1986) Int. Rev. Cytol. 105, 129-181.

17. IJsselmuiden, O. E., Herbrink, P., Meddens, M. J. M., Tank, B., Stolz, E., and Van Eijk, R. V. W. (1989) J. Immunol. Methods $119,35-43$. 